\section{NOVA TELLVS}



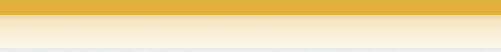

Olivares Chávez, Carolina

La presencia de los dioses en el Hiparco de Jenofonte

Nova Tellus, vol. 26, núm. 1, 2008, pp. 91-113

Centro de Estudios Clásicos

Distrito Federal, México

Disponible en: http://www.redalyc.org/articulo.oa?id=59115488003

- Cómo citar el artículo

- Número completo

- Más información del artículo

- Página de la revista en redalyc.org
Nova Tellus

ISSN: 0185-3058

novatelu@servidor.unam.mx

Centro de Estudios Clásicos

México 


\title{
La presencia de los dioses en el Hiparco de Jenofonte
}

\author{
Carolina Olivares ChÁvez \\ Universidad Nacional Autónoma de México \\ caro@servidor.unam.mx
}

RESUMEN: El tema religioso en Jenofonte ha sido abordado por varios estudiosos, y con frecuencia se ha puesto en duda si él cree realmente en las deidades o si en su obra la presencia de los dioses es superficial. Mi análisis del tratado hípico-militar Hiparco, compuesto hacia el final de la vida de Jenofonte, revela que en realidad su postura hacia los dioses es indicativa de una fe genuina.

\begin{abstract}
$* * *$
ABSTRACT: The religious aspects in Xenophon's works have been studied by several scholars, who for the most part have doubted if he actually believed in the existence of gods or if their presence in his works was rather cursory and conventional. My own analysis of the Hipparchus, a treatise on equestrian-military matters written towards the end of Xenophon's life, reveals that his attitude towards the gods betrays a genuine belief.
\end{abstract}

PALABRAS CLAVE: caballería griega, dioses, hiparco, Jenofonte, religión griega. RECEPCIÓN: 10 de enero de 2008.

ACEPTACIÓN: 2 de mayo de 2008. 


\title{
La presencia de los dioses en el Hiparco de Jenofonte
}

\author{
Carolina Olivares Chávez
}

El tema religioso en Jenofonte ha sido abordado por varios estudiosos - por ejemplo Nilsson y Anderson-, y con frecuencia se ha discutido si él cree genuinamente en las deidades o si en su producción literaria la presencia de los dioses es superficial. ${ }^{1}$ Por mi parte, considero que en este tratado hípicomilitar, integrado por 9 libros y compuesto hacia el final de su vida, el jefe de los Diez Mil expresa con claridad cuál es su postura en torno a la piedad religiosa. Luego de realizar la traducción y el correspondiente análisis de este opúsculo, encuentro lo siguiente.

\footnotetext{
${ }^{1}$ Según Nilsson, por lo que atañe a pensamientos y sentimientos verdaderamente religiosos en la obra de este estratega nada más hay frases usadas y lugares comunes (cf. Nilsson, Historia de la religiosidad griega, p. 99). Cf. la opinión de Delebecque en Xénophon, Le commandant de la cavalerie, pp. 15-16. Para Anderson, la educación religiosa y política, al igual que la instrucción moral de este autor ateniense no se caracterizaron por la especulación abstracta. El estudioso sostiene que durante toda su vida Jenofonte fue un conservador, cuya aceptación de las doctrinas y los principios que había heredado parece no inteligente o deshonesta, o ambas (cf. Anderson, Xenophon, p. 34). No obstante, argumenta que es demasiado fácil suponer que nadie puede ser sincero al profesar su creencia en cosas que nosotros mismos no creemos, y destaca la tendencia que siguen algunos escritores no totalmente contrarios a Jenofonte, quienes ven su religión como la vana repetición de vacías formalidades. En el peor de los casos, dichos estudiosos consideran que el pensamiento de Jenofonte está cargado de deshonestidad, no meramente hacia los dioses, sino hacia sus compañeros de armas. Por su parte, Anderson afirma que es más generoso suponer que su aceptación de los dioses y de las prácticas religiosas de sus ancestros era sincera (cf. Anderson, Xenophon, p. 35).
}

NOVA TELLVS, 26•1, 2008 


\section{Deberes del hiparco}

En general, conviene señalar que este breve tratado inicia y concluye con una alusión directa a los dioses. ${ }^{2}$ Desde el momento en que el comandante de la caballería asume su cargo, es preciso que siempre tenga en mente a las divinidades; esto explica el hecho de que su primera tarea consista en ofrecer un sacrificio a las deidades, para que durante su gestión lo ayuden a pensar, hablar y actuar de un modo más benévolo, más glorioso y más útil para sí mismo, para sus amigos y para la $\pi$ ó $\lambda ı \varsigma^{3}{ }^{3}$ Inmediatamente después, Jenofonte sostiene que sólo con la venia divina debe intentar sus reformas a la caballería; ${ }^{4}$ luego agrega que es preciso implorar a los dioses que sus estratagemas den buen resultado. ${ }^{5}$

En el libro VI, aclara que un buen hiparco tiene que ganarse la obediencia de sus hombres y esto lo conseguiría con mayor facilidad: "si también tuvieran en mente esto, que no los conduciría a la aventura contra los enemigos, ni sin la ayuda divina, ni contra los presagios". ${ }^{6}$

\footnotetext{
${ }^{2}$ Cf. de Equitum magistro (Eq. Mag.), I, 1-2, y IX, 8-9.

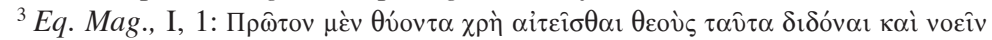

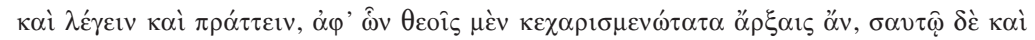

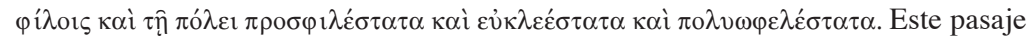
tiene su paralelo en la Anábasis, donde Jenofonte, en su calidad de jefe militar, reconoce con franqueza su piedad religiosa ante la denuncia del adivino Silano: "Yo, compañeros, ofrezco sacrificios [...] en beneficio vuestro y en el mío propio, para tener acierto al hablar, al pensar y al realizar cuanto sea lo mejor y lo más conveniente para vosotros y para mí" (cf. Xen., An., V, 6, 28, las cursivas son mías; sigo la traducción de Bach Pellicer, publicada en Gredos). Luego, en Eq. Mag., III, 1, el autor indica que, ante todo, el hiparco debe cuidar que en favor de

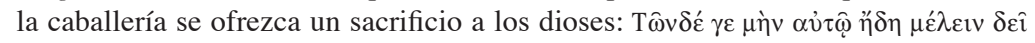



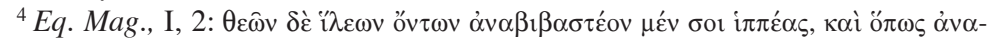

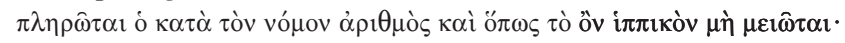

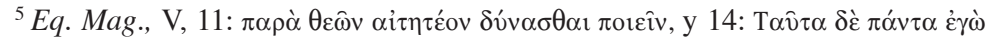

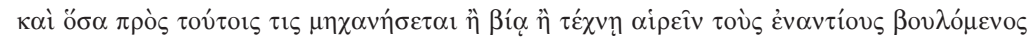

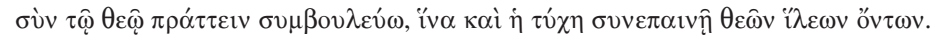

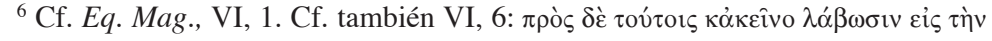

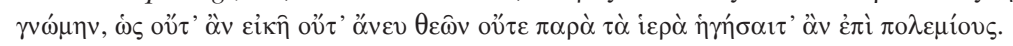


Más adelante, Jenofonte asevera que el hiparco ateniense "debe distinguirse con mucho tanto por honrar a los dioses como por ser belicoso", 7 añade que con la ayuda de las deidades debe cuidar que se ejecute lo que sabe que es bueno para el óptimo desempeño de la fuerza de caballería. ${ }^{8}$ De igual modo, debe disponer las formaciones más pertinentes para las procesiones religiosas y para las exhibiciones públicas, según el lugar donde se lleven a cabo. ${ }^{9}$

Así mismo, para que el hiparco pueda hacer reformas sustanciales al cuerpo ecuestre, es imprescindible que los dioses le sean propicios. ${ }^{10}$

\section{Procesiones y exhibiciones}

Por lo que atañe al ámbito religioso en tiempo de paz, Jenofonte aconseja lo siguiente:

es necesario que el hiparco mismo se preocupe por estas cosas: primero, porque en favor de la caballería se ofrezca un sacrificio a los dioses; después, porque durante las festividades se realicen procesiones dignas de ser vistas; y luego, porque ante la ciudad se exhiban cuantas cosas sean necesarias, de modo que en la mayor medida posible se muestren las más hermosas. ${ }^{11}$

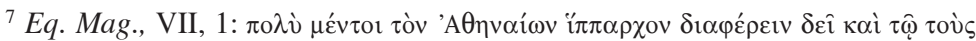

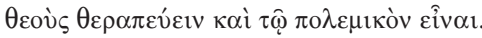

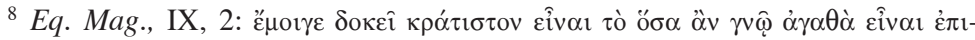

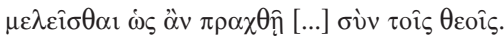

${ }^{9}$ Cf. Eq. Mag., todo el libro III.

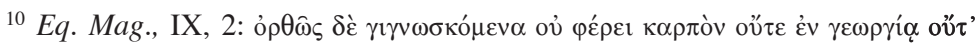

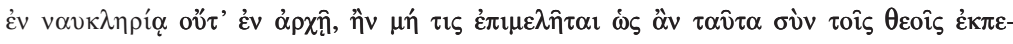

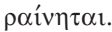



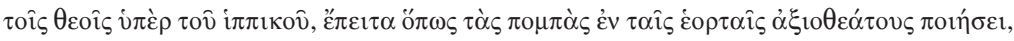

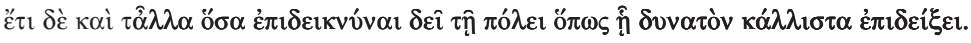


En el libro III describe minuciosamente una procesión reli-


valiosos datos sobre el papel que desempeñaba la caballería durante la celebración de las Panateneas:

Creo que las procesiones serían gratísimas a los dioses y también a los espectadores, si desde cuantos templos y estatuas hay en el Ágora, comenzando éstas por los Hermes, [los caballeros] cabalgaran en círculo en torno a ellas para honrar a los dioses. Así mismo, en las Dionisias, los coros son gratos a los restantes dioses y también a los Doce, cuando danzan.

Y luego de que vuelven a estar cerca de los Hermes, una vez que han cabalgado en círculo, desde allí me parece que es hermoso que, por escuadrones, los caballos regresen a galope hasta el Eleusino. Y no omitiré las lanzas, especialmente de qué manera se entrecruzarían unas con otras; pues es preciso que cada uno la mantenga en medio de las orejas del caballo, si es que han de ser temibles y claras, y si al mismo tiempo ha de parecer que son muchas.

Mas después de que a galope hayan terminado la cabalgata, es hermoso que ya al paso [los caballeros] cabalguen otra vez hacia los templos, como antes. Y así, ya todo cuanto hay acerca del caballo montado habrá sido demostrado a los dioses y a los hombres.

Incluso, sé que los jinetes no están habituados a ejecutar esto; pero reconozco que será bueno, hermoso y grato para los espectadores. $^{12}$

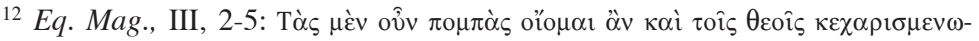

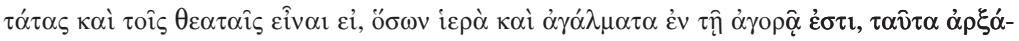

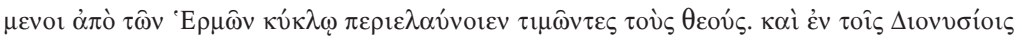

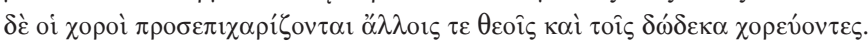

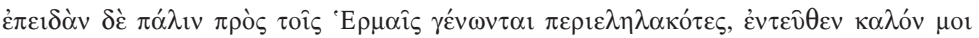



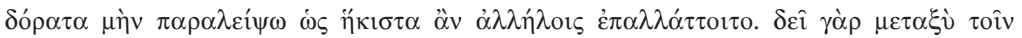



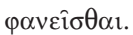

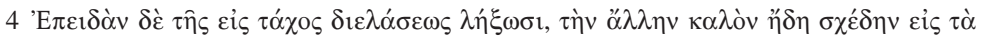





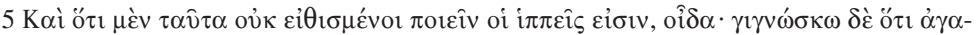




La plasticidad con que Jenofonte narra esta ceremonia a menudo ha sido interpretada como un magnífico recurso para conseguir nuevos reclutas, gracias a la espectacularidad y admiración que ante los demás ciudadanos despierta el cuerpo de caballería. Daremberg, por ejemplo, opina que con estas paradas militares la caballería quedaba bien ante la $\pi$ ó $\lambda$ s; y, puesto que Jenofonte veía que la mayoría de quienes deseaban ser hiparcos no tenían otra ambición más que lucirse durante las fiestas, los reprende, les muestra que sus funciones eran serias, que podían prestar grandes servicios a la patria y a los dioses. En este sentido, el jefe de los Diez Mil no quiere que el hiparco se luzca solo, sino con todos sus caballeros, pues la verdadera presea de un comandante de caballería es que tenga buen cuidado de su regimiento entero. ${ }^{13}$

De acuerdo con Spence, la percepción de la clase ecuestre como un grupo distinto dentro de la sociedad se reforzó con su participación en exhibiciones públicas, festivales religiosos y procesiones, que fueron las más memorables manifestaciones de la identidad corporada y social de la caballería. ${ }^{14}$

Según Salomone, Jenofonte "hace leva sobre todo por la belleza, el lustre, la pompa de los desfiles religiosos, más que por el arduo adiestramiento continuo para un arma permanente". ${ }^{15}$

\footnotetext{
La $\pi$ o $\mu \pi ́$ por antonomasia era la realizada con motivo de las Panateneas, en la que todos los ciudadanos se dirigían del Cerámico - cruzando las calles principales - hasta la Acrópolis, para ofrecer a Atenea un peplo de gala (cf. Maisch, R.-F. Pohlhammer, Instituciones griegas, p. 129).

${ }^{13}$ Cf. Daremberg, et Saglio, Dictionnaire des Antiquités grecques et romaines, t. III, p. 190, y también Xen., Eq. Mag., I, 22, donde Jenofonte atribuye esta actitud a los filarcos, no a su comandante. Por otra parte, Delebecque dice que, al parecer, Jenofonte no participó como jinete en los desfiles atenienses; quizá sólo fue un espectador y sus consejos a este respecto pretenden mejorar la calidad de las fiestas (cf. Xénophon, Le commandant de la cavalerie, p. 11).

${ }^{14} \mathrm{Cf}$. Spence, The Cavalry of Classical Greece. A Social and Military History with Particular Reference to Athens, pp. 186-187.

15 Cf. Salomone, "Letteratura, tradizione e novità tattico-strategiche nello Hipparchikos di Senofonte", en Maia. Rivista di letterature classiche, nuova serie/ fascicolo III, anno XXXVIII, settembre-dicembre, 1986, p. 201.
} 
De igual modo, Petroccelli considera que las procesiones y las paradas militares tienen un objetivo a todas luces propagandístico. ${ }^{16}$

Pese a estas opiniones, coincido con Bugh en que el esplendor de las cabalgatas durante los festivales había sido ponderado contra las exigencias de su preparación para el tiempo de guerra y la onerosa carga financiera que implicaban. ${ }^{17}$ En otras palabras, para esta época los ciudadanos ya no se dejaban arrastrar tan fácilmente por el brillo ocasional de la caballería, pues daban mayor importancia al hecho de que durante todo un año debían soportar múltiples esfuerzos físicos y económicos.

Por mi parte, considero que, si bien a Jenofonte le interesa sorprender gratamente a su público, se pierde de vista su primer objetivo, lograr que los caballeros cumplan su deber primordial: rendir honores a los dioses patrios.

En cuanto a las exhibiciones, según este tratado, unas se llevaban a cabo en la Academia, otras en el Liceo, otras en Falero y unas más en el Hipódromo. ${ }^{18}$ Conviene aclarar que Jenofonte menciona cuatro lugares, pero falta la descripción de las evoluciones efectuadas en Falero. Al respecto, Petroccelli dice que esto se solucionaría si se entendiera que en lugar de referirse a esta región, en realidad alude al hipódromo ubicado cerca de este sitio. ${ }^{19} \mathrm{Al}$ igual que las procesiones religiosas,

${ }^{16} \mathrm{Cf}$. Senofonte, Ipparchico. Manuale per il comandante di cavalleria, p. XX.

${ }^{17} \mathrm{Cf}$. Bugh, The Horsemen of Athens, p. 153.

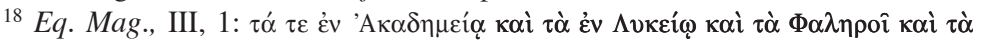
$\dot{\varepsilon} v \tau \hat{\jmath}$ i $i \pi \pi \delta \delta \rho ́ \mu \omega$. Gracias a esta obra de Jenofonte se sabe que las exhibiciones que formaban parte de la dokimasía tenían lugar en varios sitios, por ejemplo, en la Academia, en el Liceo, en Falero y en el Hipódromo; mientras la anthippasía se realizaba únicamente en el Hipódromo (cf. Daremberg, et Saglio, Dictionnaire

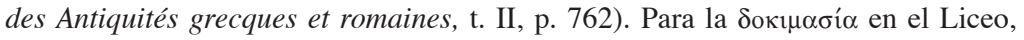

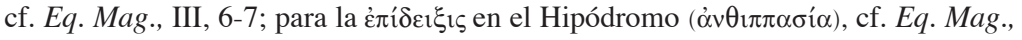

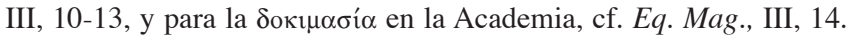

${ }^{19}$ Cf. Senofonte, Ipparchico. Manuale per il comandante di cavalleria, p. 72, n. 55 . 
estos actos ofrecían a los i $\pi \pi \varepsilon i \varsigma$ no sólo la oportunidad de lucirse y de aprobar un examen, sino además representaban el momento ideal para justificar su existencia ante el pleno de la sociedad, al mostrar que estaban bien entrenados y que constituían una opción digna de tomarse en cuenta para defender a la $\pi$ ó $\lambda$ i ante cualquier amenaza. Martin, por ejemplo, opina que éstas exhibiciones resultaban idóneas para mostrar la cantidad de habitantes que tenía la ciudad, su vigor físico, su valor intelectual, su riqueza y su patriotismo; de modo que ante tal espectáculo los aliados desistían de organizar rebeliones. ${ }^{20}$ Cabe señalar que las maniobras puestas en práctica por los i $\pi \pi \varepsilon i \varsigma$ durante las paradas militares eran parte de su preparación para la guerra. ${ }^{21}$

Con base en la descripción tan cuidadosa de tales evoluciones, varios estudiosos - entre ellos Daremberg, Spence y Salomone - opinan que estos pasajes contienen la auténtica propuesta de Jenofonte: el lucimiento de la caballería y su reafirmación como clase social, a través de exhibiciones con fines básicamente propagandísticos. El caso más representativo es el de Salomone, para quien "el aspecto espectacular de la caballería y su adiestramiento específico para los desfiles, más que promover esta arma, exalta su uso no como instrumento bélico, sino como fin de utilidad civil y medio de belleza". ${ }^{22}$

\footnotetext{
${ }^{20}$ Cf. Martin, Les cavaliers athéniens, p. 284.

${ }^{21} \mathrm{Al}$ retomar el tema de las Panateneas, vale la pena recordar que en esta fiesta tan significativa era la ciudad entera quien componía la procesión, de modo que la infantería y la caballería le daban gran vistosidad; sin embargo, además de esta función ornamental, Jenofonte ve en esta ceremonia la ocasión idónea para ejercitar y completar la instrucción de los caballeros, como manifiesta claramente en Eq.



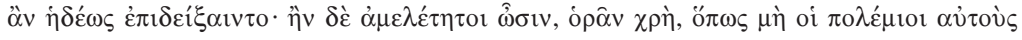

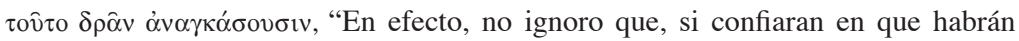
de ser capaces de galopar, muy gustosamente realizarían la exhibición; pero, si no estuviesen entrenados, es preciso cuidar que los enemigos no los vayan a obligar a hacerlo".

22 Cf. Salomone, "Letteratura, tradizione e novità tattico-strategiche nello Hipparchikos di Senofonte”, p. 201.
} 
No obstante, coincido con Petrocelli ${ }^{23}$ en que, lejos de preocuparse únicamente por la hermosura de los espectáculos ecuestres, el escritor toma en cuenta la utilidad y la eficacia que se pueden obtener de un regimiento bien adiestrado, que siempre mantiene el orden de su formación y ejecuta sus movimientos con elegancia y sincronía. En este sentido, el veterano ate-

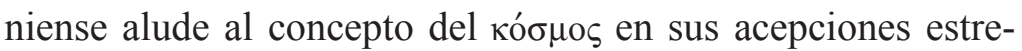
chamente unidas de orden y belleza. Con base en esto, me atrevo a afirmar que en verdad alude a la virtud jenofóntica por excelencia, la $\kappa \alpha \lambda$ $\alpha \dot{\alpha} \gamma \alpha \theta_{i} \alpha$ aplicada a esta fuerza militar: el aspecto exterior de dicha virtud radica en la belleza que produce el contemplar una formación ordenada y evoluciones realizadas de manera impecable; mientras el aspecto moral o espiritual consiste en que los caballeros persiguen un objetivo común, salvaguardar a Atenas.

\section{Los dioses y su presencia en el campo de batalla}

Si bien la observancia de los ritos religiosos es importante en tiempo de paz, se torna vital en época de guerra, porque contribuye a elevar la moral de los hombres y hace que perseveren en la lucha, dado que pelean con mayor denuedo al tener la seguridad de que las deidades están de su lado y jamás los abandonarán a su suerte.

Por lo que concierne a las actividades bélicas propiamente dichas, ante el supuesto de que los i $\pi$ ¿î $\mathrm{y}$ los soldados de infantería tuvieran que actuar en conjunto para evitar una invasión a Atenas, Jenofonte piensa que

con la ayuda divina los jinetes también serán mejores, si alguien cuida de esto como se debe, y los hoplitas no serán inferiores al tener ciertamente cuerpos más fuertes y espíritus más amantes

\footnotetext{
${ }^{23}$ Cf. Senofonte, Ipparchico. Manuale per il comandante di cavalleria, p. XX.
} 
de los honores, si se ejercitan correctamente con la ayuda divina. $^{24}$

En el libro VII Jenofonte habla específicamente de la noble empresa que debe cumplir la fuerza de caballería, defender a la $\pi$ ó $\lambda$ is en el caso de una posible invasión beocia. Gracias a los dioses, los caballeros serán mejores, si el hiparco cuida de ello como se debe, y también las deidades los auxiliarán para que puedan realizar sus planes de la mejor manera. De este modo, las maniobras antes sólo consideradas "bellas" adquieren su pleno significado, al tener como misión proteger la ciudad, sin importar que los enemigos sean más poderosos y experimentados.

Luego, en el libro VIII, al referir con lujo de detalle las funciones que desempeñarían los i $\pi \pi \varepsilon \hat{i} \varsigma$ al enfrentar a un enemigo más fuerte, Jenofonte enfatiza que vencer en la guerra es mucho más glorioso que ganar cualquier justa deportiva; pues la $\pi$ ó $\imath_{1} \varsigma$ también participa de la gloria que acompaña a los triunfos bélicos, e incluso los dioses la premian con la felicidad. ${ }^{25}$

Igualmente, cuando se preparan emboscadas y se ataca de improviso al enemigo, la intercesión de las deidades es indispensable para que todo resulte según la estrategia planeada. ${ }^{26}$ Los dioses también cuidan que los caballeros estén bien adiestrados, y puedan poner en práctica sus conocimientos teóricos. ${ }^{27}$ Por último, solamente si la divinidad lo quiere, el

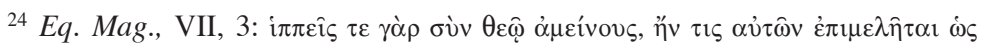

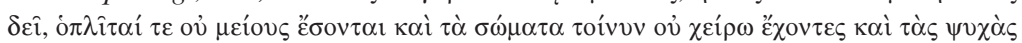

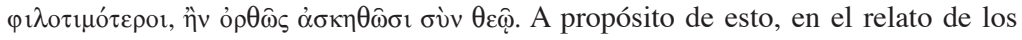
Diez Mil el autor dice expresamente que "ni el número ni la fuerza es lo que da las victorias en la guerra, sino que quienes, con la ayuda de los dioses, se lanzan con ánimo más resuelto contra los enemigos, éstos, en general, no encuentran adversario que resista" (cf. An., III, 1, 42; sigo la traducción de Gredos).

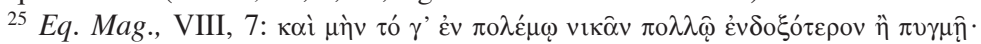

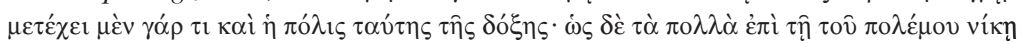

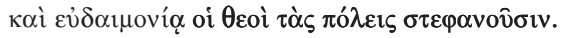

${ }^{26}$ Cf. Eq. Mag., V, 14, y VII, 14.

${ }^{27}$ Cf. Eq. Mag., VII, 3, y IX, 2.
} 
hiparco podrá instituir las reformas que Jenofonte propone en este tratado. ${ }^{28}$

Con fundamento en el pasaje de Eq. Mag., VII, 4 ( $\tau$ òv í $\pi \pi \alpha \rho-$

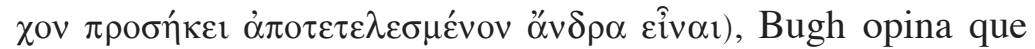
Jenofonte sugiere que la protección de los terrenos rurales de Ática era factible, mas habla de esto como si fuera una hazaña casi imposible, al necesitar la intervención de los dioses y de un hiparco brillante. ${ }^{29}$

A propósito de lo anterior, Delebecque sostiene que, si la ciudad decreta una movilización general, "existen bellas esperanzas", pues con la ayuda de los dioses los caballeros atenienses tendrán más valor que el enemigo, pero Jenofonte propone tales condiciones de entrenamiento, tanto para ellos como para la infantería, que, si rechaza todo derrotismo, permanece en el campo de la esperanza y cuenta más con la Providencia que con la forma existente de una armada organizada, lista para la acción. Más adelante el estudioso agrega que Atenas necesita la alianza entre los dioses y un hiparco que sea "un hombre completo", y Jenofonte disimula mal su dificultad para darle sus consejos. Se refugia en una pequeña paradoja: ¡más vale el pequeño número! $!^{30}$

A partir de ambos comentarios, Bugh y Delebecque consideran que Jenofonte invoca a la divinidad en los momentos cruciales de la guerra, porque en el fondo sabe que sus propuestas son imposibles. Pero disiento de ellos, pues el hecho de que pida que se tome en cuenta a los dioses al entablar un combate, lejos de implicar una derrota ineludible, indica que el caballero en cualquier circunstancia tiene que ser piadoso, máxime durante un estallido bélico. Como el propio Jenofonte afirma: "en tales circunstancias, no es posible encontrar a



${ }^{29}$ Cf. Bugh, The Horsemen of Athens, pp. 79-80, n. 2.

${ }^{30} \mathrm{Cf}$. Xénophon, Le commandant de la cavalerie, pp. 14 y 23.
} 
nadie a quien se le pueda pedir un consejo excepto a los dioses". ${ }^{31}$ Esta aseveración dura y realista adquiere su verdadero significado al recordar que se deriva de las experiencias personales del jefe de los Diez Mil. ${ }^{32}$ Frente a la incertidumbre y al miedo producidos por los horrores de la guerra, ¿quien más puede ayudar al militar que se encuentra en el campo de batalla, quién le puede infundir valor y comprender a cabalidad la sensación de fragilidad humana que lo invade, sino los dioses?

Sin embargo, desde mi punto de vista, Jenofonte no es un creyente pasivo, en el sentido de que deje todo en manos de la divinidad, en espera de que suceda lo que en términos modernos denominamos milagro, sino que está consciente y advierte que cada quien debe cumplir correctamente con sus encomiendas y esforzarse para alcanzar el triunfo, ${ }^{33}$ porque, si se hace esto, hay mayores probabilidades de garantizarse la protección divina; de lo contrario, aunque se suplique el favor de los dioses, por lógica no se obtendrá, ya que no existe una fe sincera. ${ }^{34}$ Siguiendo con este orden de ideas, los i $\pi \pi \varepsilon i \varsigma$ tienen

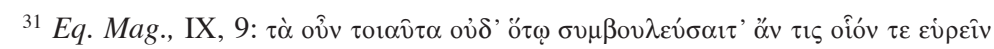
$\pi \lambda \grave{\eta} v \theta \varepsilon \hat{\omega} v$.

${ }^{32}$ Cabe mencionar que el propio Jenofonte acude a los dioses cada vez que tiene que tomar una decisión muy importante como líder del ejército mercenario: cuando todos los hombres deciden nombrar un jefe único, y muchos piensan en él, éste, indeciso en la conveniencia de aceptar tal responsabilidad, sacrifica dos víctimas a Zeus Rey, que le había sido designado por el oráculo de Delfos, y el dios, a través del sacrificio, le manifiesta que no debe pedir ni aceptar el mando (cf. Xen., An., VI, 1, 22 y 24). Luego rechaza su nombramiento y explica a los soldados el resultado del sacrificio (cf. An., VI, 1, 31). Incluso al planear Jenofonte la conveniencia de fundar una ciudad, llama a Silano de Ambracia, adivino de Ciro, y hace un sacrificio (cf. An., V, 6, 15-17). Igualmente, cuando duda si debe apartarse del ejército junto con sus hombres, durante un sacrificio Heracles Conductor le dice que no se separe (cf. An., VI, 2, 15).

${ }^{33}$ Cf. Vernant, El hombre griego, p. 19.

${ }^{34}$ Vale la pena señalar que, en la Ciropedia, Jenofonte manifiesta claramente que los dioses no conceden peticiones absurdas: si no se sabe montar a caballo, es imposible que concedan una victoria hípica; si no se ha prevenido la guerra, es ilógico pedir la salvación en ella (cf. Cyr., I, 6, 5). 
que actuar de manera congruente con lo que piensan. No tiene ningún sentido que imploren la ayuda de las deidades, cuando no se preocupan por honrarlas como conviene, por observar sus ritos religiosos y sin creer verdaderamente en ellas. Considero que es aquí donde adquiere auténtica relevancia su participación en las procesiones religiosas, pues al demostrar lo que saben y son capaces de hacer se esfuerzan principalmente por agradar a los dioses. ${ }^{35}$ Por esta razón, no es gratuito que Jenofonte le advierta al hiparco que tiene que distinguirse con mucho por honrar a los dioses y por su belicosidad, ${ }^{36}$ ya que para solicitar el auxilio divino es preciso que él mismo, en su calidad de jefe de la caballería, ponga todo su empeño en planear una buena estrategia, en superar los problemas y, de forma simultánea, sea piadoso tanto en la teoría como en la práctica. Pero, ¿cómo puede ser piadoso en la práctica? Además de cumplir voluntariamente con los ritos religiosos y de participar en las procesiones, tiene que poner atención en los mensajes enviados por los dioses, ya que "ellos saben todo y lo anuncian de antemano a quien ellos quieren: a través de sacrificios y augurios, de oráculos y sueños". 37

Cabe recordar que Diógenes Laercio afirma que este autor era piadoso, amante de los sacrificios y experto en interpretarlos; ${ }^{38}$ en consecuencia, Jenofonte habla con conocimiento de causa.

\footnotetext{
${ }^{35}$ A propósito de esto, Vernant comenta que a los dioses se les celebra por medio de procesiones, cánticos, danzas (cf. Vernant, El hombre griego, pp. 17-18). Jenofonte da prueba de ello al realizar un símil entre la caballería y los coros que participan en las Dionisias, con cuyas danzas resultan gratos a los dioses (cf. Xen., Eq. Mag., III, 2).

${ }^{36}$ Cf. Eq. Mag., VII, 1.

${ }^{37}$ Eq. Mag., IX, 9: oป̂ं

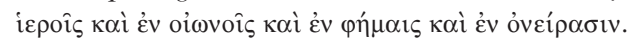

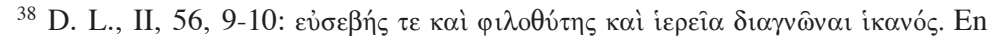
relación directa con esto, Petrocelli sostiene que también aquí se presenta otro rasgo peculiar de Jenofonte: su piedad, aquel sentimiento que parece practicar, casi conjugando la obediencia a una religiosidad ortodoxa con el respeto de las directrices de la enseñanza socrática (cf. Senofonte, Ipparchico. Manuale per il comandante di cavalleria, p. XXXIV). Por otro lado, Glover añade que "Xenophon,
} 
Debido a su trayectoria militar, a Jenofonte mejor que a nadie le consta que los hombres muestran una mejor disposición anímica cuando ven y están convencidos de que sus superiores acatan los designios que los dioses les expresan mediante los sacrificios, los oráculos y los sueños. ${ }^{39}$

El vínculo entre las actividades bélicas y lo sagrado radica en la necesidad de una garantía de la protección divina, motivo por el cual, fuera al inicio de la guerra o durante las cam-

of course, knows the forceful character when he meets him, but in all his books he makes it clear that a man's position is stronger and his head clearer, if he will use such means as he can to supplement himself whit the knowledge of what the gods' will is and to secure their support and inspiration. He sacrifices perpetually, he consults the oracle, he has a mantis at his side, he watches for oriens - all this, though the most practical and business-like of men" (cf. Glover, From Pericles to Philip, p. 173).

${ }^{39}$ También en la Anábasis el autor da muestras de su piedad: ante las continuas insidias, a instancias de Jenofonte y con el apoyo de los adivinos, los capitanes purifican el ejército (cf. Xen., An., V, 7, 35). Alude a la importancia de cumplir los juramentos hechos ante los dioses (cf. An., III, 1, 21). Jenofonte ofrenda su parte de diezmo a Apolo y la consagra en el tesoro de los atenienses en Delfos y en Escilunte, ya desterrado, construye un altar y un templo dedicados a Artemisa (cf. An., V, 3, 4-13). Para poder retornar a Atenas, y con el tiempo llegar a tener dinero, el adivino Euclides le aconseja que haga un sacrificio a Zeus Miliquio ("acogedor de sacrificios expiatorios"). Al día siguiente realiza otro sacrificio y quema unos lechones según la costumbre de sus padres, ante su resultado favorable, unos hombres aportan dinero para el ejército y le devuelven su caballo, que había vendido al verse obligado por la necesidad (cf. An., VII, 8, 3-5). Finalmente, al volver a Pérgamo, Jenofonte va a saludar al dios. Para esto, los lacedemonios, los capitanes, los demás estrategos y los soldados acordaron darle una parte selecta del botín, de manera que incluso estaba en condiciones hasta de hacer un favor a otro (cf. An., VII, 8, 23).

Este discípulo de Sócrates da testimonio de otro tipo de presagios: una vez electo como uno de los estrategos, justifica su ataque a los bárbaros por su perjurio e infidelidad; cuando termina de hablar, alguien estornuda en señal de buen augurio. Lo interpreta como favorable e interrumpe su discurso para ofrecer sacrificios a Zeus Salvador y a los demás dioses según sus posibilidades (cf. An., III, 2, 8-9). De inmediato continúa su arenga y manifiesta que es obvio que los dioses están de su lado y no con los perjuros. Añade que gracias a la intercesión divina se puede superar cualquier situación angustiosa (cf. An., III, 2, 10). También considera que el ocultamiento del sol presagia el fin de un imperio (cf. An., III, 4, 8). Según este autor ateniense, el incendio de una casa es un presagio del dios (cf. An., V, 2, 24-27). 
pañas, la observación de los presagios como manifestación del cielo era fundamental. Eso explica que, cuando un ejército se dirigía al campo de batalla, le seguían adivinos, quienes en toda ocasión importante hacían sacrificios e interpretaban tales señales. ${ }^{40}$ Una de las funciones de los ritos sacrificiales era fomentar la disciplina, la solidaridad y el valor, indispensables para sobrevivir al enfrentamiento bélico. Se efectuaban en el campo o en la ciudad antes de salir hacia la batalla; en el curso de estos sacrificios los presagios tenían que ser interpretados como favorables antes de que la acción pudiera comen-



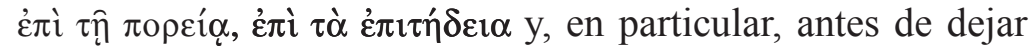
el campo para entablar el combate. ${ }^{41}$ Los términos usados son


tas a consultar los presagios, y i $\varepsilon \rho \alpha$ son las partes sagradas del animal sacrificado; en sentido más amplio, equivale a sacrificios hechos con fines adivinatorios antes de una empresa. ${ }^{42}$

\footnotetext{
${ }^{40} \mathrm{Cf}$. Nilsson, Historia de la religiosidad griega, p. 101. Los sacerdotes eran consultados en asuntos privados o públicos tanto por los generales en campaña como por los fundadores de colonias (cf. Bloch, La adivinación en la Antigüedad, p. 43).

${ }^{41}$ En el relato de la expedición de los Diez Mil, antes de iniciar la batalla Jenofonte hace un sacrificio (cf. An., VI, 5, 12), y antes de que salga la expedición realiza otro cuyo resultado es positivo (cf. An., VI, 4, 9, y VII, 2, 15-17). Cf. Xen., Ages., I, 31, donde, tras hacer un sacrificio, Agesilao arremete contra sus enemigos.

${ }^{42}$ Cf. Pritchett, The Greek State at War. Part I, pp. 110 y 111. En la página 115 dice que la atención que Jenofonte presta al arte adivinatorio está en armonía con sus continuas referencias a los dioses en su exposición de materias militares.

En cuanto a la iєробколía (inspección de las víctimas), ésta se basaba en el estado de las entrañas, en especial del hígado, de la bilis, del bazo y de los pulmones, se observaba cómo se quemaban en el altar y cómo se deslizaba el humo despedido por el sacrificio (cf. Maisch, R.-F. Pohlhammer, Instituciones griegas, p. 113). Cf. Xen., Lac., 13, 2-5, allí se describe paso a paso la manera en que se llevaba a cabo un sacrificio antes de salir con el ejército. Jost señala que Jenofonte a menudo se hace eco de una armoniosa alianza entre el estratega y su mantis (cf. Jost, "Guerre et religion", en Pallas. Revue d'études antiques. Guerres et sociétés dans les mondes grecs à l'époque classique, no. 51, 1999, p. 133).
} 
En cuanto a la adivinación basada en los pájaros, ésta consistía en interpretar el vuelo y el grito, la actitud y el movimiento de las aves; de manera que ciertas deidades tenían como mensajeros a determinados pájaros, de preferencia aves de presa, las más poderosas y las más rápidas, como el águila de Zeus, el cuervo de Apolo, o la lechuza de Atenea. Otras aves traían presagios con su aparición, sus actos imprevistos, sobre todo, durante la realización del sacrificio, cuando el dios manifestaba su aceptación o su rechazo. ${ }^{43}$

Por lo que toca a la oniromancia, en el ámbito castrense sólo se consideraba significativo lo que soñaba el jefe de los soldados, pues se pensaba que sus sueños se relacionaban estrechamente con el desarrollo de la contienda. Los antiguos griegos creían que ésta era una forma mediante la cual los dioses le revelaban su voluntad al líder. ${ }^{44}$

Sobre la trascendencia que tenían para este autor griego los ritos sacrificiales, es oportuno mencionar que en la Anábasis se encuentran ejemplos como los siguientes: uno de los adivinos aconsejó a Jenofonte que ofreciera una víctima al viento, hizo el sacrificio y cesó el aire (cf. An., IV, 5, 4). En otra ocasión, cruza un río confiando en las víctimas, porque los adivinos le habían dicho que habría combate, pero el final de la expedición sería favorable (cf. An., V, 2, 9). Incluso cuando está en peligro de que lo maten, tras un sacrificio a Zeus Rey, ya casi al término de la obra, éste le aconseja que se marche (cf. An., VII, 6, 44).

${ }^{43}$ Cf. Bloch, La adivinación en la Antigüedad, pp. 13-14 y 44. Respecto a la oí ñal positiva; hacia el lado izquierdo era negativa (cf. Maisch, R.-F. Pohlhammer, Instituciones griegas, p. 113). Si bien en el tratado hípico-militar Jenofonte no aporta más detalles acerca de esta clase de adivinación, en la Anábasis refiere lo siguiente: cuando partió de Éfeso para ser presentado a Ciro, un águila graznaba a su derecha, aunque estaba inmóvil. El adivino que lo acompañaba dedujo que "se trataba de un presagio importante -impropio de un hombre vulgar-, glorioso pero laborioso, porque los pájaros, sobre todo, atacan al águila cuando está quieta: sin embargo, no era un presagio que prometía dinero, porque el águila volando captura mejor a sus presas" (cf. An., VI, 1, 23, sigo la traducción de Gredos). Posteriormente, el adivino Arexión de Parrasia ve un águila de buen augurio y exhorta a Jenofonte para encabezar la marcha (cf. An., VI, 5, 2).

${ }^{44}$ Nada más se tomaban en cuenta los sueños de los subordinados cuando varios soñaban algo similar (cf. Pritchett, Greek State at War. Part III, pp. 94-95).

A lo largo de la Anábasis se citan varios casos donde a través de los sueños las deidades recomiendan la estrategia más conveniente; cabe decir que es el propio 
Gracias a este conjunto de señales divinas, el jefe podía tomar decisiones importantes para que su misión fuera exitosa. ${ }^{45}$ Consciente de que a veces los adivinos se dejaban sobornar, Jenofonte, está convencido de que un buen jefe debe tener nociones de adivinación, para no dejarse manipular por los demás, ${ }^{46}$ pues la interpretación de estas señales divinas tenía serias repercusiones en el ánimo de los soldados. Dicha observación se deriva de las desagradables experiencias que vivió en Asia Menor, donde en varias ocasiones tuvo que enfrentar a los soldados, enardecidos a causa de las insidias de algunos de sus propios hombres. ${ }^{47}$

Sin embargo, no bastaba con comprender los designios de las deidades, sino que era necesario acatarlos. Cuando un presagio era adverso, el ejército debía permanecer en el mismo sitio y su comandante no debía iniciar las hostilidades hasta que, luego de repetir los sacrificios, obtuviera resultados favorables; si por algún motivo el líder contravenía la voluntad divina y entablaba el combate, esto equivalía a elegir el suicidio colectivo, algo imperdonable, ya que la principal función del jefe consistía en procurar el bien de la comunidad, en este caso, el bien de su regimiento y de la $\pi$ ó $\lambda ı \varsigma^{48}$

Jenofonte quien los descifra y los comunica a sus hombres (cf. An., III, 1, 11-14, y IV, 3, 8-9, seguido de su respectivo sacrificio y presagio favorable). En otro pasaje, él mismo ofrece libaciones a los dioses que le mandaron el sueño y la solución de cómo pasar un profundo río (cf. An., IV, 3, 13).

${ }^{45}$ En otra obra de Jenofonte, Cambises enfatiza que un buen líder debe ser piadoso y debe observar los designios divinos, también subraya la importancia de que el propio jefe sepa descifrar las señales divinas, a fin de no depender de los adivinos y que éstos lo engañen; de este modo, al reconocer lo que los dioses mandan, podrá obedecerlos (cf. Cyr., I, 6, 3).

${ }^{46}$ Cf. Xen., An., V, 6, 29.

${ }^{47}$ Cf. An., V, 6, 28-33.

${ }^{48}$ En la Anábasis destaca un caso en el cual, tras muchos intentos negativos, finalmente el sacrificio para que prosigan la marcha es favorable (cf. An., VI, 5, 2). Sin embargo, también hay ejemplos donde aunque se repita el acto sacrificial los resultados siempre son adversos; sobresale un pasaje en el cual intervienen todos los adivinos del ejército y todos los soldados supervisan el ritual para que no haya 


\section{Conclusiones}

Tras analizar esta obra de Jenofonte, encuentro que su religiosidad es genuina, pues es producto de sus convicciones y experiencias personales, como él mismo declara:

Si alguien ve esto con sorpresa, que con frecuencia se ha aconsejado actuar con la ayuda divina, sepa bien que cuando a menudo se corre peligro, esto le causará menos extrañeza; y si considera que cuando hay guerra los enemigos traman asechanzas unos contra otros, pero rara vez saben cómo están las asechanzas. ${ }^{49}$

Sin duda la piedad es una virtud esencial para Jenofonte, que incide en todos los ámbitos de la vida humana, pero no concuerdo con Jaeger, quien afirma que el guerrero de Jenofonte es el hombre que confía lisa y llanamente en Dios, ${ }^{50}$ cual un creyente pasivo. Por el contrario, con base en sus vivencias como soldado de caballería y mercenario, este escritor sabe que, para tener autoridad moral sobre los subordinados, es muy importante que quien los comanda sea congruente entre lo que piensa, lo que dice y lo que hace, de manera que para exigir

dudas, incluso Jenofonte nombra a otra persona para que dirija la ceremonia, pero ni eso modifica el resultado (cf. An., VI, 4, 13-26; otros casos negativos en V, 5, 3, y VII, 1, 40).

Cambises, en la Ciropedia, recomienda encarecidamente a su hijo no actuar nunca en contra de los presagios y augurios, no arriesgar ni la vida propia ni la de los soldados, pues los hombres a partir de conjeturas proyectan sus empresas, sin saber de cual de ellas obtendrán bienes (cf. Cyr., I, 6, 44). Le recuerda a Ciro algunos casos donde hombres que se consideraban sabios actuaron en contra de los designios y se atrajeron grandes infortunios para sí y a veces para su pueblo, alude en especial a Creso (cf. Cyr., I, 6, 45).

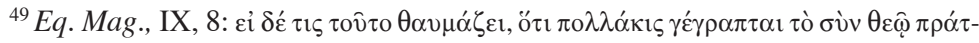
$\tau \varepsilon 1 v, \varepsilon v \hat{~}$

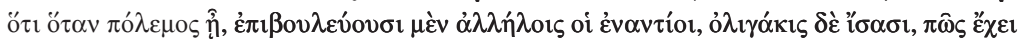

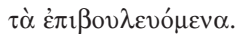

${ }^{50}$ Cf. Jaeger, Paideia. Los ideales de la cultura griega, III, p. 210. 
algo debe ser capaz de hacer esto que pide, y ya que sólo se puede aprender la virtud al tener trato con alguien virtuoso y emularlo, es evidente que la personalidad del hiparco ejerce en esta obra un papel pedagógico, por eso es él quien tiene que distinguirse por su piedad en todo momento, tanto con actos como con palabras. Porque, como Jenofonte dice ya para concluir su opúsculo:

Es natural que prefieran aconsejar a éstos que no sólo les preguntan qué conviene hacer cuando lo necesitan, sino que también en la prosperidad veneren a los dioses en la medida de sus posibilidades. $^{51}$

De lo anterior se desprende que, para conseguir el favor de las deidades, es menester que no se les invoque nada más para pedirles favores, sino que en cada instante de la vida pública y privada hay que ser piadoso, y esta piedad debe reflejarse en los pensamientos, en las palabras y en las acciones cotidianas. A todas luces, Sócrates influyó en la formación intelectual y moral de Jenofonte, pero esto no significa que su discípulo haya mantenido una postura acrítica con respecto a las enseñan-



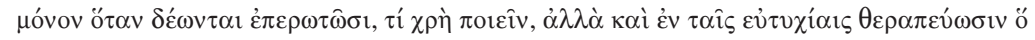

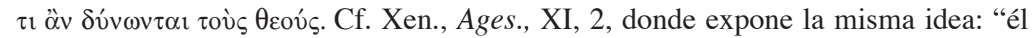
(sc. Agesilao) nunca dejó de proclamar su creencia de que los dioses no se contentan menos con actos piadosos, que con víctimas puras". Sigo la traducción de Guntiñas Tuñón, publicada en Gredos.

Durante una conversación con su padre, Ciro añade que puede tener más influencia tanto cerca de los dioses como de los hombres, aquel que no les adula cuando está en dificultades, sino que se acuerda de los dioses, sobre todo, cuando las cosas le salen según sus planes (cf. Cyr., I, 6, 3). En otro pasaje, Cambises reconoce que "la sabiduría humana no sabe en modo alguno elegir lo mejor [...], en cambio, los dioses por eternos, saben todo: el pasado, el presente y lo que resultará de cada uno de los acontecimientos, y, de entre los hombres que los consultan, a aquellos a quienes se muestren más propicios les anuncian lo que es necesario hacer y lo que no. Y si no quieren aconsejar a todos, no es nada extraño, pues no están obligados a ocuparse de los que no quieran" (cf. Cyr., I, 6, 46; sigo la traducción de Vegas Sansalvador, publicada en Gredos).
} 
zas del filósofo, sino que, en mi opinión, retomó varias ideas de su maestro a causa de que comulgaba con ellas, ya que se adecuaban a su propia naturaleza y a su propia forma de pensar. Por mi parte, considero que al componer esta obra, el jefe de los Diez Mil reflexiona y escribe lo que su espíritu le dicta, lo que su experiencia le aconseja y lo que le consta que funciona, pues él mismo lo ha puesto en práctica a lo largo de su existencia.

\section{BIBLIOGRAFÍA}

\section{Fuentes antiguas}

Diogenes Laertius, Lives of eminent philosophers II, english transl. R. D. Hicks, Cambridge, Harvard University Press (The Loeb Classical Library), 1970.

Jenofonte, Anábasis, intr. Carlos García Gual, trad. y nts. Ramón Bach Pellicer, Madrid, Gredos (Biblioteca Clásica Gredos, 52), 1991.

-, Ciropedia, intr., trad. y nts. Ana Vegas Sansalvador, Madrid, Gredos (Biblioteca Clásica Gredos, 108), 1987, 510 págs.

-, Obras menores (Hierón, Agesilao, La República de los lacedemonios, Los ingresos públicos, El jefe de la caballería, De la equitación, De la caza). Pseudo Jenofonte, La República de los atenienses, intrs., trads. y nts. Orlando Guntiñas Tuñón, Madrid, Gredos (Biblioteca Clásica Gredos, 75), 1984.

Senofonte, Ipparchico. Manuale per il comandante di cavalleria, intr., trad. e note Corrado Petrocelli, appendice: P. G. Joly de Maizeroy. Quadro generale della cavalleria greca, Bari, Edipuglia (Quaderni di "Invigilata lucernis", 14), 2001.

XÉNOPHON, Le commandant de la cavalerie, texte établi et traduit Édouard Delebecque, Paris, Société d'Édition "Les Belles Letres", 1973.

Xenophon, Scripta minora, english transl. E. C. Marchant, Cambridge, Harvard University Press (The Loeb Classical Library), 1946.

\section{Fuentes modernas}

Anderson, J. K., Xenophon, London, Bristol Classical Press, 2001² (1a. ed., 1974). 
BLoch, Raymond, La adivinación en la Antigüedad, trad. Víctor Manuel Suárez Molino, México, Fondo de Cultura Económica, 2002.

Bugh, Glenn Richard, The Horsemen of Athens, Princeton, Princeton University Press, 1988.

Daremberg, M. Ch., et E. SAglio, Dictionnaire des Antiquités grecques et romaines, t. II. Première partie (D-E), Graz, Akademische Druck-U. Verlagsanstalt, 1969.

-, Dictionnaire des Antiquités grecques et romaines, t. III. Première partie (H-I-J-K), Graz, Akademische Druck-U. Verlagsanstalt, 1969.

GERnET, Louis, y André BOUlANGER, El genio griego en la religión, trad. Serafín Agud Querol y J. A. Díaz-Regañón López, México, UTEHA, 1960 (2a. ed. española).

Glover, T. R., From Pericles to Philip, London, Methuen and Co. LTD, 1924 (4a. ed.).

JAEGER, Werner, Paideia. Los ideales de la cultura griega, III, vrs. española Wenceslao Roces, México, Fondo de Cultura Económica, 1949 (2a. ed. esp.).

Jost, Madeleine, "Guerre et religion", en Pallas. Revue d' études antiques. Guerres et sociétés dans les mondes grecs à l'époque classique, Toulousse, Pallas et Presses Universitaires du Mirail, no. 51, 1999, pp. 129-139.

Maisch, R.-F. Pohlhammer, Instituciones griegas, trad. del alemán Willhelm Zotter, Barcelona-Buenos Aires, Editorial Labor, 1951.

Martin, M. Albert, Les cavaliers athéniens, Paris, Ernest Thorin (Bibliothèque des Écoles Françaises d'Athènes et de Rome), fascicule 47, 1887.

MCK. CAMP II, John, Horses and Horsemanship in the Athenian Agora, American School of Classical Studies at Athens (Excavations of the Athenian Agora Picture, Book No. 24), 1998.

NiLsson, Martin P., Historia de la religiosidad griega, Madrid, Gredos, 1953.

Olivares Chávez, Carolina, Ética y milicia en Acerca del Hiparco de Jenofonte, estudio, trad. y nts., México, Facultad de Filosofía y Letras, Universidad Nacional Autónoma de México, 2005 (tesis de maestría).

PlÁCIDO, Domingo, La sociedad ateniense. La evolución social en Atenas durante la guerra del Peloponeso, Barcelona, Crítica, 1997.

Pritchett, W. Kendrick, The Greek State at War. Part I, Berkeley-Los Angeles-London, University of California Press, 1974.

-, Greek State at War, Part III, Berkeley, University of California Press, 1979. 
NOVA TELLVS, 26•1, 2008, pp. 91-113

SAlOMONE, Serena, "Letteratura, tradizione e novità tattico-strategiche nello Hipparchikos di Senofonte", en Maia. Rivista di letterature classiche, nuova serie/fascicolo III, anno XXXVIII, settembre-dicembre, Bologna, Nuova Casa Editrice Licinio Cappelli, 1986, pp. 197-205.

Spence, I. G., The Cavalry of Classical Greece. A Social and Military History with Particular Reference to Athens, Oxford, Clarendon Press, 1993.

VERnANT, Jean-Pierre, y otros, El hombre griego, Madrid, Alianza Editorial, 2000. 